Revista Iberoamericana, Vo1. LXXXII, Núm. 254, Enero-Marzo 2016, 27-43

\title{
CAPITALISMO Y PRODUCCIÓN DE SUBJETIVIDAD EN MANO DE OBRA Y FRUTA PODRIDA
}

\author{
POR \\ CÉSAR ZAMORANO \\ University of Pittsburgh
}

El análisis del capitalismo actual, como horizonte de posibilidad y de existencia de todo lo que acontece, ha sido objeto permanente de estudio desde diferentes ámbitos de discusión. Sociólogos, filósofos, economistas, políticos y, en general, una inmensa colección de materiales ha sido inspirada por esta marcha creciente del devenir contemporáneo. De esta forma, el presente trabajo tiene por objeto una reflexión de este esquema paradigmático del capitalismo actual. Creemos que es necesario y urgente poner en circulación discursos que intervengan en el auto-asumido reconocimiento de lo inevitable del capitalismo, no para desmentir esta inevitabilidad, sino más bien, para desmontar los ejes sobre los cuales esta certeza ha sido instalada.

Este trabajo pretende ser una reflexión de las condiciones de posibilidad que el capitalismo actual ha impuesto sobre las producciones de subjetividad. Determinar cómo se establecen esos marcos de referencia dentro de los cuales los sujetos habitan, radicadas dentro de los márgenes de una sociedad capitalista. Para ello, consideraré dos novelas que permitirán identificar las coordenadas desde las cuales circulan los sujetos actuales: Mano de obra de Diamela Eltit (2002), y más reciente aún, la novela de Lina Meruane Fruta podrida (2007), dos obras de escritoras chilenas que, bajo sus particulares miradas, nos invitan a observar las travesías de un Chile modernizado, que ha sabido asumir su papel fundacional de un capitalismo bárbaro y global.

\section{Dos NOVELAS, DOS ACERCAMIENTOS}

Mano de obra, publicada en el 2002, es capaz de manifestar la producción de sujetos de un capitalismo bárbaro. Bajo la figura del mercado, Eltit construye la compleja región de nuestra contemporaneidad como lugar donde circulan los flujos de producción, los deseos y las relaciones que se establecen entre ellas. Eltit construye un referente metafórico de un sistema total articulado en y desde la figura del Capitalismo. La obra 
está dividida en dos capítulos donde se articulan voces distintas, registros diferentes de tonalidades y pertenencias, que se expresan desde un afuera y un adentro del supermercado, sin que este afuera signifique, de ninguna manera, una posible salida. La primera parte, "El despertar de los trabajadores (Iquique, 1911)", se centra en una sola voz, la del protagonista, delimitada por un incesante y complejo procedimiento ritual, se presenta en un primer plano la voz quejumbrosa de un cuerpo lacerado por una constante vigilancia. Todo ello, en el escenario total del supermercado como lugar alegórico de una sociedad actual por donde transitan los sujetos, y que en la novela se denomina súper, aludiendo doblemente a una suerte de apodo familiar, pero también a la noción de lugar espectacular donde se puede conseguir todo lo necesario para vivir. La segunda parte del libro, "Puro Chile (Santiago, 1970)", se desarrolla fuera del supermercado, específicamente en la casa donde habitan los protagonistas, para representar una suerte de comunidad de emergencia. Los personajes son definidos en el relato en cuanto a las funciones que ocupan en el súper: cada gesto de sus reemplazables vidas remite a la localización espacial dentro del mapa de productividad (la promotora, la trozadora de pollos, el supervisor). Su existencia precaria sigue estrechamente enlazada, en todos ellos, con un cuerpo social atravesado por los flujos de producción. Nadie escapa a esta filiación perversa que los obliga a estar en constante alerta frente a alguna de las manifestaciones de desprendimiento de esta configuración con el súper.

Por otra parte, la novela de la escritora chilena Lina Meruane, Fruta podrida, publicada en 2007, obtuvo el premio del Consejo Nacional del Libro a la mejor novela inédita en el año 2006. En ésta, su penúltima novela, la autora de Las infantas (1998), Póstuma (2000), Cercada (2000) y su recientemente aparecida Sangre en el ojo (2012), da cuenta de la experiencia de los sujetos insertos en un sistema de producción. Radicada hace algunos años en Nueva York, Lina Meruane forma parte de las escritoras que surgieron de los talleres literarios de Diamela Eltit y que paulatinamente ha logrado construir su propia voz. Los críticos que atacan sistemáticamente las obras y la persona de la escritora Diamela Eltit, desprecian no sólo las obras de Meruane, sino también de la escritora Andrea Jeftanovic ${ }^{1}$ y Nora Fernández, entre otras. Conocidas maliciosamente como "las diamelitas", han debido luchar contra una academia literaria chilena que,

1 Andrea Jeftanovic (Santiago de Chile, 1970) ha publicado las novelas Escenario de guerra (2000; Premio Juegos Literarios Gabriela Mistral y Consejo Nacional del Libro) y Geografia de la lengua (2007), y un volumen de cuentos, No aceptes caramelos de extraños. Como autora ha sido invitada a las Ferias del Libro de Guadalajara 2004, Lima 2005, y a eventos literarios en Colombia (2006) y Cuba (2008). Ha recibido becas de pasantía para estadías en Brasil, Portugal y España. Ha participado en antologías nacionales y extranjeras. Actualmente escribe un libro de entrevistas y testimonios con apoyo del Fondart, titulado Conversaciones con Isidora Aguirre (2009), y de ensayo; Hablan los hijos. Estéticas y discursos en la perspectiva infantil en la literatura contemporánea (2011).

Revista Iberoamericana, Vol. LXXXI, Núm. 254, Enero-Marzo 2016, 27-43 
pasando por Bolaño y Fuguet, ${ }^{2}$ han sistemáticamente negado, muchas veces a priori, los aportes de estas nuevas escritoras a la escena literaria chilena. ${ }^{3}$

En Fruta podrida, el relato se centra en las hermanas María y su hermana Zoila, la Mayor y la Menor, respectivamente. La primera, una mujer entregada completamente a su trabajo en una empresa de exportación de frutas, se encarga de erradicar las plagas de las frutas para ser exportadas. Mantenerlas en perfecto estado, preservarlas para su consumo, constituye su labor fundamental, lo que con abnegada entrega permite que la empresa produzca frutas globalizadas que circularán por el mundo. Producción que no se da en el plano exclusivo de su función laboral, en el cual se afana religiosamente, sino también produciendo hijos que luego serán vendidos al hospital con fines de investigación para trasplantes. Zoila, su hermana menor, aquejada de una enfermedad incurable que la mantiene alejada de la producción, desarrolla su existencia saboteando su propia existencia, acrecentando su enfermedad, que sólo puede ser curada con la ayuda de los avances de la medicina y los trasplantes. La Mayor, al percatarse de la carencia de reconocimiento de su trabajo en el engranaje del capital, de su completa entrega a preservar el sistema al cual cree pertenecer, la lleva a atentar contra la fruta que debe proteger. Con el dinero ahorrado por la venta de los hijos de la Mayor, Zoila se va hacia un país del norte, supuestamente en busca de su padre que nunca regresó. Sin embargo, la intención de este viaje es otro. Zoila, con su compulsiva tendencia a la auto aniquilación, comienza a eliminar a otros pacientes en el hospital. El desenlace final es presentado en la voz imparable de un nuevo personaje que entra en escena. Una enfermera de un prestigioso hospital que, en un interminable diálogo con Zoila, más cercano a un monólogo delirante, cierra el conjunto de nudos que habían quedado sueltos durante el relato. La novela termina cuando la enfermera revisa el pie de Zoila que se ha podrido al igual que las frutas que han sido saboteadas por su hermana.

2 En su Blog, en noviembre 11del 2005 Fuguet escribe lo siguiente "No es que nadie asesinó a Diamela Eltit, la otrora 'reina de la academia', sino más bien, ocurrieron dos cosas: Diamela Eltit empezó a escribir sobre supermercados (ver Mano de obra) y, por lo tanto, sin querer, según un profesor pop, ella ingresó a un territorio que quizás antes consideraba 'enemigo'. Dos: los profesores y doctores en literatura nueva se criaron con tele, cómics y cine".

3 Véase como ejemplo la respuesta a un artículo de La Tercera, donde un autor anónimo de un periódico de Chile hace eco de los comentarios virulentos contra Lina Meruane y otras escritoras que surgieron en los talleres de Diamela Eltit. En él, Meruane responde: "La nota que ahora me cautiva apareció el sábado pasado en el suplemento cultural de La Tercera. El anónimo redactor 'informaba' sarcásticamente sobre un asunto privado y delicado: que los manuscritos de tres escritoras acaban de ser rechazados por Planeta. La nota comienza caricaturizando a Nona Fernández, Andrea Jeftanovic y a la que aquí firma como 'fervorosas' seguidoras de Diamela Eltit, igualándolas en un culto supuestamente compartido y en una misma devoción al estilo 'diameliano'. Concluye que si no hemos logrado editar es por ser malas copias de la 'original'. ¿Graciosa la agresión? Más patética que insultante, más mediocre que perversa”, en Lina Meruane, "Más Mediocre Que Perverso".

Revista Iberoamericana, Vol. LXXXII, Núm. 254, Enero-Marzo 2016, 27-43 ISSN 0034-9631 (Impreso)

ISSN 2154-4794 (Electrónico) 
De La COMUNIDAD A LO PRIVAdo (DE)

Eltit y Meruane focalizan su mirada crítica a los espacios construidos por un Chile moderno, cosmopolita, donde los productos transitan desde el resto del mundo a Chile, y desde Chile al mundo. Se presenta un Chile sin memoria, donde el rasgo fundamental de los personajes de ambas novelas es la dependencia al sistema laboral al cual pertenecen, que estructura casi por completo su subjetividad. Los espacios recreados en estas novelas se encargan de conseguir que esta dependencia sea evidente. El mercado establece las leyes y los roles que cada uno de nosotros representaremos en el gran teatro de la sumisión.

Los dispositivos mediante los cuales el capitalismo se redefine constantemente permanecen alertas, vigilantes ante las posibles intervenciones que se puedan producir al interior de sistema. Las matrices de organización social no se han abierto a una explosión de diversidad, dando pie a mayores y diversos modos de organización social a las ya debilitadas organizaciones sindicales, partidistas o religiosas. Más bien, se han tipificado precisamente en la figura del precio, de la capitalización de los deseos y fuerzas que los individuos son capaces de sostener. Para Guattari, la reconstrucción constante de los modos de apropiación del capitalismo es una de las características esenciales del capitalismo actual,

El Capitalismo Mundial Integrado no se obstina en recomponer, de acuerdo a nuevas formas de unificación, los flujos y las jerarquías de los poderes estatales tradicionales. Engendra funciones estatales suplementarias que se expresan a través de una red de organizaciones internacionales, una estrategia planetaria de los medios de comunicación de masas, una rigurosa toma de control del mercado, de las tecnologías, etc. (165)

En Mano de obra, el supermercado adquiere una dimensión absoluta que no sólo domina la experiencia laboral del protagonista, sino fundamentalmente, desarrolla su completa subjetividad al servicio de una religión del capital. Así, el súper se convierte en la figura hegemónica de la dominación de la sociedad capitalista que ya no intenta generar esperanzas, no hay promesas ni voluntades sosegadas por un mundo mejor, sino más bien, el puro artificio de la abyección que, como forma consumada de existencia, se torna necesaria y total. El espacio del súper se enquista radicalmente en la experiencia de los personajes de la novela, especialmente del protagonista, donde incesantemente la funcionalidad que le ha sido asignada le permite de alguna manera construir una precaria, neutra y sustituible subjetividad, "[c]on una paz desmedida me radico como un objeto neutro en el pasillo, satisfecho por mi humor controlado pero, al fin y al cabo, saludable" (37).

La sociedad de control presentada en estas novelas conduce al establecimiento central de una economía de la vida, destinada ya no a ejercer su dominio en el ejercicio de su

Revista Iberoamericana, Vol. LXXXII, Núm. 254, Enero-Marzo 2016, 27-43 ISSN 0034-9631 (Impreso)

ISSN 2154-4794 (Electrónico) 
capacidad de limitarla por la violencia de la muerte como límite, sino en la producción de la vida, su organización, su potenciación dentro de un aparato ya no centralizado por el estado, sino más bien, por los flujos de producción por donde transitan los cuerpos y las pulsiones. Para Foucault, este es un poder regulador que se aplica no al cuerpo individual, sino al ser humano como especie. "El poder reside y se ejerce en el nivel de la vida, de la especie, de la raza y de los fenómenos masivos de población" (166). La preservación de la vida y de sus flujos se convierte en una figura destinada a actuar por sobre la permanencia de la vida en sus diferentes formas, disminuyendo el carácter ético de la preocupación, aumentando la permisividad ética, pero igualmente totalizante. Siguiendo esta idea de Foucault, Fernando Blanco plantea el carácter desechable de la experiencia individual en los medios de producción. Insiste en que

[a]l mismo tiempo las nuevas formas de administración de la soberanía, la decisión sobre quién debe vivir o morir agrega un nuevo componente a este escenario: los ciudadanos son desechables al igual que la política. La sustituibilidad unida a la incertidumbre salarial constituyen los vectores sobre los cuales se arman las nuevas formas de socialización y vinculación intersubjetiva obrera. (174)

Nada escapa al capitalismo, puesto que no hay un discurso que se quiera imponer, no hay letras que deban inscribirse en los cuerpos para ser sometidos. El sometimiento se resuelve en que todo acto es capaz de ser convertido en capital. Así, nuevas formas de poder son desplegadas bajo este influjo sagrado. Un poder global que en Mano de obra se ha metaforizado bajo la figura de la luz del súper. "Bajo la vigilancia de esta luz entera e insidiosa (pero, claro, una luz divina) que pareciera provenir desde ninguna parte, que digo, del mismo espectro de un Dios más que terminal proviene" (Eltit 58).

El espacio apremiante y total del súper que establece las subjetividades de los personajes, no se resuelve fuera de ella. No pueden existir sino como sujetos de un sistema perverso que los apresa. También el espacio privado de la casa, contaminado por las fuerzas dominantes de precariedad de las relaciones sociales, y por tanto, convertido en un espacio donde se reproducen los flujos de poder y los vicios sociales, ha sido uno de los tópicos recurrentes en la obra de Eltit. Lo encontramos principalmente en $\mathrm{El}$ cuarto mundo y Los vigilantes, y de manera sostenida y como tema central en Jamás el fuego nunca (2007). Bernardita Llanos atiende a la contaminación de los espacios privados en las obras de Eltit, donde plantea expresamente que,

[c]omo institución, [la familia] está traspasada por el poder y las pulsiones, convertida en espacio de agresión y degradación. Así también la casa adquiere diversos sentidos que se oponen al ideal hegemónico y que la presentan como intemperie o prisión espacio de la mirada panóptica que borra cada vez más las fronteras entre lo privado y lo público. (133)

Revista Iberoamericana, Vol. LXXXII, Núm. 254, Enero-Marzo 2016, 27-43 ISSN 0034-9631 (Impreso)

ISSN 2154-4794 (Electrónico) 
En la novela de Eltit ya no hay fronteras que separen los desapegos funcionales que han perdido toda su potencialidad en la experiencia de lo público y el trabajo, transformando la estructura del refugio de la casa, del hogar en un lugar de emergencia donde se reproducen las mismas condiciones de poder que en los espacios públicos prevalecen. Las turbulencias de las familias, los conflictos profundos de la familia chilena desarrollados en gran parte de la obra de Eltit, son transformados en Mano de obra en espacios transitorios, donde los personajes se ligan unos a otros por la conveniencia y la posibilidad de sobrevivir. Ya no hay madres e hijos en conflicto, sino funcionarios que cohabitan un mismo espacio, mostrando con ello la penetración del capitalismo en las esferas más privadas de la sociedad actual. Michael Lazzara atiende a esta condición cuando afirma que "la segunda mitad -'Puro Chile (Santiago, 1970)': el título evoca el pináculo de la solidaridad obrera y el poder popular bajo Allende-enfoca la penetración del neoliberalismo en el espacio privado de la casa" (161). Lo anterior plantea uno de los elementos más desarrollados por los críticos de esta novela: el contraste entre los títulos de la novela, que refieren a fechas y momentos de la historia sindical y de luchas sociales en Chile del último siglo, en oposición a la precariedad y ausencia de proyectos comunes en los trabajadores de la transnacional sociedad actual. ${ }^{4}$ Dicotomía que Mónica Barrientos reconoce entre Historia e historia como "la constatación de un vacío o ausencia de un sujeto de trabajo que no posee un discurso, que no pertenece a una clase definida ni posee una historia que lo identifique" (26).

En Fruta podrida, el espacio degradado de la casa y del trabajo mantiene a la Mayor en una constante y absoluta productividad. No sólo se encarga de evitar cualquier riesgo de contaminación de la fruta, sino que su acto de filiación sistémica se concentra casi con mayor fuerza en su casa donde hay una batalla imperiosa por la pulcritud, la higiene. En este sentido, irrumpen las moscas como figuras inquietantes, que deambulan, se posan en las cosas a pesar de los esfuerzos de la Mayor por erradicarlas de su esterilizada existencia. Pero ni las moscas ni la enfermedad de su hermana, ni la huelga de las temporeras dejan de zumbar, inquietando su precaria existencia.

Al igual que en la novela de Eltit, los personajes de Fruta podrida mantienen una similar dependencia sistémica que se manifiesta constantemente en la figura de María, la Mayor, que nunca renuncia a su condición de supervisora, de preservadora de las frutas y de los peligros que la aquejan. La metáfora de la fruta sirve entonces para reconocer el carácter de los sujetos sometidos a un sistema que los define, los restaura,

4 Este argumento es desarrollado a lo largo de los textos de Blanco y Lazzara. Para Cánovas el carácter alegórico de la novela se relaciona con la noción teológica de Caída, que no deja de rememorar la idea de ruina benjaminiana. Comenta que es "[a]legoría de una sociedad de entes cosificados bajo la ley neoliberal; alegoría teológica sobre los límites de la condición humana. [...] Orfandad de grupo, colectivo que no se protege a sí mismo, restilandia, la supresión de los afectos en la lucha darwiniana”, 30.

Revista Iberoamericana,

Vol.

L X X XII,

Núm.

254

Enero-Marzo

$2016, \quad 27-43$ 
los preserva para ser sustituidos por otros, procesados en serie: "El mundo puede ser un gran galpón lleno de gente diversa. El mundo allá abajo es una enorme instalación fabricando ciudadanos de exportación" (Fruta podrida 120).

Todos los lugares en que se desarrolla la trama de la novela, la empresa de exportación, el hospital, la casa, son espacios que se superponen y se someten a una economía global de la eficiencia y la sumisión irrestricta a un orden, a una racionalización de las experiencias humanas. Este sometimiento a las condiciones de posibilidad ofrecidas por un sistema genera un sentido de pertenencia y dependencia que obra de tal manera que obliga a atacar cualquier posibilidad de dislocación, de alteración del proceso de conservación y consumo: "Esa hermana que se moja los labios con la punta de la lengua y suspira no contempla la posibilidad de que me niegue a sus cuidados, que me niegue a la inmortalidad, que prefiera una libertad de corto plazo" (Fruta podrida 71).

\section{PRoducCión DE SUBJeTIVIDADES: ETERNIZANDO EL PRESENTE}

En ambas novelas se puede percibir un elemento central de las sociedades capitalistas actuales: no hay límites como horizontes de existencia en los individuos sometidos a la trama de la producción. Ambas obras son capaces de desarrollar una nueva e inquietante tendencia existencial, al interior del marco referencial del capitalismo, producida por un conjunto de aparatos y dispositivos culturales y económicos que rediseñan las coordenadas en las cuales han vivido los sujetos. La reflexión de Heidegger en torno a las formas de subjetivación de los sujetos, considera que el elemento fundamental del Dasein es la temporalidad en la que se sienten inmersos. El Dasein, por existir sin una esencia delimitada de antemano, se constituye como proyección hacia un futuro, pero con un pasado constantemente presentizado. Así, la limitación de la muerte como horizonte de posibilidad marcaría la temporalidad generando un campo de existencia. "En semejante estar vuelto hacia su fin, el Dasein existe en forma propia y en su integridad, como aquel ente que él -'arrojado en la muerte'- puede ser. El Dasein no tiene un fin en el que solamente termine, sino que existe de un modo finito" (Heidegger 347). La existencia humana como totalidad es establecida por su mortal terminación. Así el Dasein, al asumir su finitud surge como posibilidad, como un conjunto articulado entre su nacimiento y su muerte. Sin embargo, Paul Ricoeur discute la limitación de este postulado cuando se pregunta "¿Qué constituye el ser total del Dasein? El ser para la muerte, en efecto, sólo clarifica el 'ser para el fin', pero deja completamente en la incertidumbre aquello que constituye la 'cohesión' propia de la vida [...] la prolongación, la extensión de la vida” (201). Creo que Ricoeur apunta al hecho paradigmático que para Heidegger la existencia se define en un hacia, en un por-venir, lo que para Heidegger constituye la unidad del Dasein a través de la resolución precursora de un estar vuelto hacia la muerte. De modo que la vida emerge como proyección especular con la muerte.

Revista Iberoamericana, Vol. LXXXII, Núm. 254, Enero-Marzo 2016, $27-43$ ISSN 0034-9631 (Impreso)

ISSN 2154-4794 (Electrónico) 
Para los personajes de Mano de obra, la finitud de la existencia no forma parte del conjunto de matrices desde los cuales construyen su existencia, son sujetos incorporados al interior de una sociedad capitalista, ciudadanos de derecho, funcionarios establecidos por sus referencias sociales y fundamentalmente laborales, que no lidian con la muerte. En ellos, la muerte como hecho constante, efectivo y patente no articula sus existencias, no establece su identidad como horizonte de posibilidad. Representados como funcionarios del súper, la temporalidad para los personajes se convierte en un continuo inacabable. El tiempo es sentido aquí como una eternización del presente, donde no se vislumbra un fin que delimite el conjunto de manifestaciones que constituyen los sujetos capitalizados como fuerza de trabajo, como mano de obra.

Más horas. Más tarde aún. Sin embargo todavía sigo parapetado [...] las horas son un peso (muerto) en mi muñeca y no me importa confesar que el tiempo juega de manera perversa conmigo porque no termina de inscribirse en ninguna parte de mi ser. Sólo está depositado en el súper, ocurre en el súper. (31)

Tenemos un tiempo permanente, que obstinadamente rehúsa abandonar al protagonista, en una economía donde los cuerpos son preservados artificialmente, lo sabemos, como los productos del supermercado que son mantenidos hasta lo imposible para el ejercicio del consumo. Pero inmediatamente otros serán los que ocupen su lugar como una constante que neutraliza ese punto de término. Los sujetos/clientes/trabajadores/ funcionarios/productos son sustituibles, continuables y, por tanto, el tiempo permanece y la muerte es relegada y neutralizada. Es el tiempo que se obstina en permanecer, no quiere irse y junto con ello nosotros no podemos sino soportar eternamente sin la conciencia de que terminará en algún momento.

La finitud de la existencia humana ya no constituye un elemento esencial de asignación de sentido. La ilusión y la esperanza de una eternidad de la vida, de una eternización de un presente inacabado, permanente, donde los sujetos pueden ser sustituidos unos por otros, preservando intacto el sistema. La vida se hace permanente, la muerte se convierte en un fenómeno privado, familiar, oculto e indeseado, pero no determinante para la propia existencia. La muerte, no está disponible ni como consuelo ni como desgracia; los sujetos en ambas novelas viven sometidos eternamente a este devenir que no terminará pronto.

La fruta, en la novela de Meruane, es el eje que enlaza la dimensión económica y la producción de la vida de los sujetos. Y esta identificación entre la fruta y los sujetos se evidencia precisamente en la nomenclatura y las prácticas médicas que, una vez más, Zoila es capaz de percibir. El sistema organizado de la producción de fruta y del hospital se obstina en aceptar la muerte como resolución de la vida. La inmortalidad, o por lo menos, el imparable devenir de los sujetos y los productos se constituyen en la meta de la ciencia médica. El cuerpo se convierte en el campo de batalla donde deben

Revista Iberoamericana, Vol. LXXXII, Núm. 254, Enero-Marzo 2016, 27-43 ISSN 0034-9631 (Impreso) ISSN 2154-4794 (Electrónico) 
lidiar las fuerzas sociales que realizan todo tipo de artificios para ahuyentar la muerte. María, cuando asiste a la oficina del médico, se da cuenta de la extraña relación que se establece entre la práctica médica y la producción en serie cuando describe la oficina del Director del hospital, la cual estaba "llenas de grandes botellas y de relucientes órganos embotellados, tan perfectos que parecían plásticos, tan rozagantes que más que órganos humanos parecían frutos en conserva. Fruta perfecta como las que ella estaba produciendo cada temporada en el campo" (Fruta podrida 22).

En la misma novela, en el relato final, la enfermera de un prestigioso hospital conversa con la protagonista, ahora convertida en una mendiga que se encarga de atentar contra los enfermos en el hospital, al igual que su hermana lo hizo con las frutas en la empresa de exportación. En este casi monólogo (ya que la protagonista casi no pronuncia palabra alguna), la enfermera expresa el carácter atemporal de la manzana que le ofrece a la protagonista cuando afirma que,

[y]a le expliqué que son todas igualitas estas manzanas tan lustrosas e indistinguibles unas de otras que unas veces tiene la ilusión de que son plásticas. No sabe lo que duran en refrigerador, ¡meses! Esta perfectamente podría ser una manzana errante del siglo pasado: una manzana inmigrante que no sabemos adónde va ni de dónde viene ... (Fruta podrida 171)

Del mismo modo, en Fruta podrida, la metáfora de su propio título nos sitúa en una relación especular con la muerte y la terminación de la vida. Así lo plantea la propia Meruane al reflexionar en torno a su novela:

Más que la diabetes misma, que me interesaba, sin duda, por su relación simbólica con la fruta, lo que quise explorar en esta novela fue la biopolítica actual. Este tema me parece crucial porque la política sobre la vida y la muerte atraviesa todos los discursos y encarna en los cuerpos. En nuestros cuerpos, en su materialidad. Partiendo del caso particular de la diabetes fui abriendo la mirada hacia una cuestión más panorámica para encontrarme con el hecho paradójico de que asistimos simultáneamente a la mercantilización del cuerpo y a su más radical devaluación. (Meruane, "Todo sobre la peste")

Pero la obstinada tendencia a la permanencia no sólo se da en el plano de los productos, en el plano paradojal del consumo, sino también en las epistemologías de la ciencia médica que transitan en Fruta podrida. Al igual que María, el Médico General del hospital forma parte de los dispositivos de la preservación de la vida a toda costa. Meruane reconoce en este sentido una filiación entre el saber de la ciencia médica y el capitalismo moderno que Foucault identificó con la biopolítica. “ ¿Su hermana medias, morirse?', repitió el Médico palideciendo aún más y balbuceó: morirse nadie. Sobre mi cadáver se morirá alguien en este hospital. ¿Para qué cree que estamos trayendo tanta máquina, tanta tecnología importada contra la muerte?” (Fruta podrida 23).

Revista Iberoamericana, Vol. LXXXII, Núm. 254, Enero-Marzo 2016, 27-43 ISSN 0034-9631 (Impreso)

ISSN 2154-4794 (Electrónico) 
La “ontología sublime” de Heidegger no funciona como referente de sentido en la vida de los personajes de ambas novelas. Más bien todo el sistema está determinado por la lucha contra todo límite, es un intento constante por la suspensión del punto final, del fuera de, para adentrarnos en un presente interminable, en la dinámica de la repetición constante, la sustitución de unos sujetos por otros, por la permanencia.

\section{LA RELIGIÓN DEL CAPITAL}

Benjamin plantea que el capitalismo se constituye como religión pues comprende tres ejes de relación. Por un lado, el capitalismo es una religión de puro culto: "[i] $\mathrm{n}$ the first place, capitalism is a purely cultic religion, perhaps the most extreme that ever existed" (288). No pide adhesión a un dogma en particular, no le interesa, sino que funciona como puro acto. No necesita sujetos homogeneizados ideológicamente; permite que los individuos puedan construir su identidad de diversos modos. Lo que el capitalismo exige es el sacrificio de todas aquellas formas de existencia en el altar de la bolsa y la economía.

Un segundo aspecto religioso del capitalismo sería el total y permanente ejercicio del culto: "[c] apitalism is the celebration of a cult sans reve et sans merci [without dream or mercy]" (Benjamin 288). Los sujetos dentro del capitalismo no pueden escapar de este orden, pues cada uno de los actos y prácticas conducen a su profundización. De esta manera, la valoración religiosa del trabajo como eje de significación de la identidad de los sujetos ejerce una presión sobre los individuos, sin tregua y sistemáticamente.

Por último, la noción más compleja de Benjamin es la idea de que el capitalismo es una religión donde no hay esperanza, sino sólo culpa y abyección: "[ $\mathrm{t}]$ he cult makes guilt pervasive. Capitalism is probably the first instant of a cult that creates guilt, not atonement" (288). Benjamin constata (siguiendo a Nietzsche) que la totalización de este sistema donde no hay un afuera, la culpa se convertirá en el referente sustancial de la experiencia humana. Hermann Herlinghaus expresa la ligazón de esta improfanación con la angustia y desesperación que éstas generan: "In the sphere of social fantasies as emotional projection, the desire to consume is paralleled by an overall sense of depression in view of the increasing difficulty in making 'profane' use the world" (Herlinghaus 27).

La afirmación del carácter desesperanzador del culto capitalista es desarrollada por Benjamin y violentamente puesta en escena por Eltit y Meruane. Los individuos son sometidos al interior de este engranaje donde no hay redención posible. Lo propio de este sistema no es la expiación, sino más bien la universalización de la culpa. Las relaciones de intercambio con el mundo se convierten en liturgias de una constante sacralización de las cosas en la esfera de una economía de relaciones. La repetitividad aquí vendría a servir como ejercicio de mnemotecnia que, a diferencia de otras épocas donde la letra se inscribía con sangre, ahora se recurre al incesante artificio de la repetición

Revista Iberoamericana, Vol. LXXXII, Núm. 254, Enero-Marzo 2016, $27-43$ ISSN 0034-9631 (Impreso) 
y el espectáculo. "No estoy enfermo (en realidad) sino que me encuentro inmerso en un viaje de salida de mí mismo. Ordeno una a una las manzanas. Ordeno una a una las manzanas. Ordeno una a una (las manzanas)" (Eltit 55).

El capítulo "El Obrero Gráfico" de Mano de obra es uno de los más reveladores de la experiencia cúltica del capitalismo, donde se manifiesta de modo grotesco el carácter paródico de un culto ritual, de la naturaleza sacrificial del capitalismo. Los sujetos se presentan ante un escenario donde cada uno representa un papel dentro de una esfera paradójicamente sagrada. La figura de Dios se instala en el sitio mismo de la repetición y los cuerpos: "estoy poseído por un Dios que me invade con un brillo que me ubica en la mira ávida de todos los presentes" (Eltit 62). El Dios se ha hecho nuevamente carne, pero ahora el sacrificio y el martirio ha sido asignado a los hombres que deben recrear el rito para disolverlo, traspasar los cuerpos. "Dios está en todas partes. A lo largo y ancho de mi cuerpo"(62). El más acá de la figura divina adquiere un carácter revelador cuando se posesiona de los sujetos y de manera insolente muestra impúdicamente los cuerpos y los productos destinados al consumo. El sacrificio ahora se presenta al interior del protagonista de manera brutalmente corporal y erotizada:

Mi Dios (mi diosito lindo) me lo concede porque soy el padre de su hijo y como suplemento [...] cumplo con el oficio histórico que le fue asignado a la puta. Yo soy (también) la niña obscena que va a enderezar su alicaído senil miembro [...] Viejo Dios impotente. (62)

El supermercado se convierte en un templo donde se realiza el ritual de la sacralización de los productos. Tanto los sacerdotes como los feligreses forman parte de esta obra divina dentro de este espacio: “En el súper, claro, de qué otro modo, pues, estaría yo encabezando la miseria de esta gloria que me ha sido concedida.”(67) Hay una inevitabilidad del sistema capitalista que, sin necesidad de ningún tipo de promesa escatológica, es capaz de atrapar a los sujetos para hacerlos no sólo sus víctimas, sino también sus cómplices.

Por otro lado, Giorgio Agamben pone en circulación la noción de consumo y espectáculo como ejes centrales del capitalismo moderno. Para Agamben, lo esencial de la religión no es la capacidad de unir, aludiendo a la raíz latina religare como comúnmente se ha afirmado, sino más bien, el carácter intrínsecamente disociador de ésta. Agamben advierte que lo propiamente religioso está determinado por la separación en que se encuentra lo profano y lo mundano. Es en la práctica del rito donde se produce este espacio diferenciador entre el mundo sagrado y el mundo profano. Así, el rito es entendido como sacramento, que dice relación con lo sagrado (Eliade 19).

Ahora bien, el carácter sagrado está definido por ese espacio que lo diferencia del mundo, entonces tenemos que el referente de lo sagrado se posesiona en el capitalismo como un espacio de poder, jerárquicamente establecido, alejado del uso de los hombres

Revista Iberoamericana, Vol. LXXXII, Núm. 254, Enero-Marzo 2016, $27-43$ ISSN 0034-9631 (Impreso)

ISSN 2154-4794 (Electrónico) 
y por tanto, poderosamente sublime, intocable. Los individuos son incapaces de aprehenderlos, ya que el poder los ha confiscado a una esfera diferente que no está disponible para el uso común. De ahí que el mecanismo de profanación, a grandes rasgos, tendría por función la restitución al uso común de los hombres de manera tal que lo profanado nuevamente es incorporado a la economía del uso.

Según Agamben, la restitución al uso del mundo entendido como producto a ser consumido se tornaría imposible: “[e]l consumo, que destruye necesariamente la cosa, no es sino la imposibilidad o la negación del uso, que presupone que la sustancia de la cosa quede intacta" (108). Sin lugar a dudas, el consumo es en nuestra sociedad un paradigma de relación no sólo con las cosas, sino también con los cuerpos, deseos y actividades que mantienen a los individuos en una relación de no pertenencia con el mundo. El consumo configura una relación imposible con el mundo, puesto que se produce en el preciso instante de su destrucción, quedando sólo el vacío y la obligatoriedad de llenarse nuevamente: "[p] or lo tanto, no se lo puede tener si no en el instante de su desaparición" (108). El consumo permite que se establezca constantemente de modo interminable la preservación del carácter improfanable del sistema de relaciones que giran en torno al capital. El consumo se convierte en el acto mismo de ese fuera de uso.

El carácter improfanable del capitalismo se puede visualizar desde la dinámica de la muerte en Fruta podrida. Hay una recurrente resistencia de los personajes a la finitud, exceptuando a la Menor que conlleva el germen de la disidencia y la enfermedad. La eternidad de un presente interminable, sistémico nos ofrece un continuum de la vida bajo el desprecio de nuestra precaria individualidad. La permanencia que entra en escena es la de la repetición, de la preservación del organismo social, pero asimismo es la ausencia del horizonte como posibilidad. Es el puro y más absoluto ejercicio de la privación de un por-venir, en tanto es el presente quien condiciona la existencia, del proceso por el cual estructuralmente, de una manera sistémica radica nuestra subjetividad. De ahí que la experiencia cúltica del capitalismo nos enmarca al interior de la dinámica de la culpa planteada por Benjamin, y la muerte es sustituida por la invalidez, la improductividad que constituye la inexistencia al interior del sistema capitalista.

\section{LA BATALLA DE LOS CUERPOS}

Dentro de toda esta economía de la permanencia, en ambas novelas se abren espacios de disidencia que siempre están relacionadas con el carácter corporal y pulsional de los sujetos. El carácter productor de subjetividad, que Guattari resuelve como fundamental para comprender el capitalismo actual, actúa también como el espacio de resistencia aún posible para subvertir el orden de lo establecido. Si bien el error del sicoanálisis fue considerar la dualidad sociedad-público-represión y pulsión-individualidad-privado como dos esferas que se oponían dialécticamente para conciliarse en un yo social,

Revista Iberoamericana, Vol. LXXXII, Núm. 254, Enero-Marzo 2016, 27-43 ISSN 0034-9631 (Impreso)

ISSN 2154-4794 (Electrónico) 
Guattari comprende que es en el plano de las pulsiones donde el capitalismo actúa como productor de subjetividades y deseos. Es en el cuerpo donde se establecen y se gravan nuestras pulsiones identitarias que los personajes de ambas novelas desarrollan como filiación a los medios de producción a los cuales pertenecen. Es María, la Mayor, quien ejerce un incesante control no sólo sobre las frutas, sobre la producción de ellas, sino también es precisamente en el espacio privado de la casa, donde obsesivamente actúa para erradicar todo contagio, toda enfermedad que pueda alterar lo inalterable. Es en el escenario de los cuerpos fraccionados, serializado donde se establecen las construcciones sociales que dan origen a la identidad de los sujetos. Asimismo, y a pesar de ello, no puede sino ser el cuerpo el campo en el que se expresan las posibles desarticulaciones y las puestas en suspenso de la producción de subjetividad capitalista.

La metáfora de la enfermedad de su hermana y la descomposición, plagas y un conjunto de elementos que atentan con la permanencia se convierten en los enemigos que ella debe erradicar con sus venenos y sus fármacos. La descomposición y la enfermedad no tienen derecho de ciudadanía en el globalizado mundo del capital. Los sujetos, al igual que los productos, deben ser eficientes, constantes, funcionales para ser aceptados. Es por ello que la Mayor, ante la enfermedad de su hermana, se encuentra inquieta y recurre a un sinnúmero de acciones tendientes a erradicar la enfermedad que le consume la vida a su media hermana: "María se levantó con náuseas: iba a tener una enfermedad metida dentro de su propia casa, la enfermedad se le había colado y no había manera de erradicarla" (Fruta podrida 28).

Los espacios de resistencia en ambas obras son limitados, sin embargo, emergen a pesar de constituir un desastre que lleva a la anulación de las propias identidades de los individuos. Cualquier acto fuera de orden constituye su propia aniquilación, pero siempre ligado a las pulsiones del cuerpo. El protagonista de Mano de obra constantemente alude a su estado de enfermedad que lo lleva a la sensación de no pertenencia al súper. Es un deseo que se cuela por las redes permeables del sistema de producción: "[m]i deseo (mi último deseo) es derrumbarme en medio de un estrépito más que irreverente y así arrastrar conmigo a una hilera interminable de estantes para que las mercancías sean, finalmente, las que me lapiden" (52). La alusión al deseo de subvertir el orden, de alterar la simetría de los estantes constituye el incesante espacio que no es aún aniquilado por la luz del súper: "Ah, si no estuviera atado a la desagradable metafísica de esta voz mía incesante y terminal cascada que me retumba mis propios oídos (mi voz casi inaudible que me habla de manera monótona a mí mismo. De mí)" (56).

Hay otros momentos en la novela de Eltit donde se producen ciertas alteraciones a la estructura serial del súper. Por ejemplo, el personaje de la promotora que comienza a despreocuparse de ella misma, comienza a mostrar su propia descomposición, manifestando el agotamiento en su propia carne que impúdicamente se muestra como transitada por el tiempo. Asimismo, pero con mayor intensidad Gabriel, el reponedor, es

Revista Iberoamericana, Vol. LXXXII, Núm. 254, Enero-Marzo 2016, 27-43 ISSN 0034-9631 (Impreso)

ISSN 2154-4794 (Electrónico) 
el personaje que se presenta como línea de fuga, que inquieta constantemente al grupo con sus quejas y sus críticas. En él hay una conciencia de su descontento y un intento visible ante los otros de esa congoja. Isabel es la única a la que le gusta esa expresión de descontento que se manifiesta en Gabriel en la palpitación de su ojo: "es que el ojo le late a este concha de su madre porque todavía está vivo, respirando" (151).

Zoila también altera el esquema de producción atentando contra su propio cuerpo. La enfermedad entonces es vista como disidencia. Es precisamente esto lo que explica el médico a María acerca de la enfermedad de su hermana cuando afirma que:

[1]o que ha atentado contra su hermana es su propio sistema defensivo, conjeturó el médico, es como si ese sistema hubiera sufrido un lapsus, un trastorno, un golpe de Estado, y en su paroxismo se hubiera dedicado a aniquilar las propias células que lo mantienen vivo. (Fruta podrida 24)

La relación entre enfermedad, cuerpo y sistema social de producción comienza a enlazarse precisamente cuando Zoila, la Menor, intenta zafarse de su propia reproductividad, de la pervivencia de su organismo. La enfermedad entonces, la mantiene privada de la pertenencia al organismo social y, por tanto, constituye un problema, un peligro a la rutinaria pertenencia de su hermana: "Esa hermana que se moja los labios con la punta de la lengua y suspira no contempla la posibilidad de que me niegue a sus cuidados, que me niegue a la inmortalidad, que prefiera una libertad de corto plazo" (Fruta podrida 71). Si para Foucault el poder de dar vida y preservar la vida es el carácter sustancial de las sociedades capitalistas actuales, a diferencia del derecho a dar muerte de los poderes feudales y reales precapitalistas, la función de la muerte y la enfermedad constituyen un fuera de orden, una dislocación al sistema biopolítico de dominio capitalista. La enfermedad, la contaminación de las frutas, producen un colapso a la persistencia del sistema: "[1] os médicos le aseguran a María que mi desobediencia es provocada por un gen hereditario. La desobediencia es otra enfermedad congénita, también irremediable" (71). Pero Zoila y su hermana saben que el precio por la disidencia es alto. El aislamiento, el exilio, el ostracismo constituyen los rasgos de una existencia que combate el orden de producción capitalista. “¿Dónde viven los desterrados?” (46), pregunta Zoila a su hermana sin obtener respuesta alguna, como queriendo saber dónde se encuentra el lugar que ella misma debe habitar.

El cuerpo como un perfecto sistema de producción, la enfermedad como deficiencia del sistema identificando al elemento que hay que sustituir o extirpar. El capitalismo es precisamente ese mismo sistema de producción biopolítico que reconoce como ejes centrales ya no el sujeto, su dominación y disciplinamiento, sino a la población como masa perteneciente a un sistema que debe funcionar. De ahí que la medicina moderna construye el modelo de salud pública, no del individuo, sino de la población, del control de la natalidad, de la eliminación de contagios masivos, de la estructuración de

Revista Iberoamericana, Vol. LXXXII, Núm. 254, Enero-Marzo 2016, 27-43 
la sociedad para evitar el colapso de los medios de producción que generan riquezas. Nuevamente en la voz de la enfermera resuena esta misma idea cuando afirma que "[n] osotras amamos la vida cada vez más, las guaguas de probeta más y más, la inmortalidad de los trasplantes, la clonación terapéutica y también regenerativa con células madre" (Fruta podrida 149).

Del mismo modo, la movilidad del tiempo en ambas novelas comienza a adquirir velocidad en el momento inexorable del desapego, de la ruptura con el sistema de permanencia. Es la inminente ruptura con un orden total lo que produce en los personajes de Fruta podrida la apertura hacia un tiempo que se mueve y ya no se detiene. Con ello, los personajes comienzan a formar parte de una historia, donde ellos mismos se constituyen en agentes que propician un devenir que no sólo los posee, sino que también les pertenece. Lina Meruane reflexiona lo siguiente en torno a este punto:

Es algo siempre difícil de aceptar, y pienso que la tecnología actual está intentando calmar esas angustias proponiendo una serie de medidas que están alterando la noción de vida y muerte, y los tiempos en que suceden estos procesos. En esta novela yo vi la descomposición como el mecanismo que revela a los personajes en profundidad, ante sí mismos: la certeza del final detona las decisiones de cada personaje. ("Todo sobre la peste")

El tiempo estático, inamovible de gran parte de novela de pronto comienza a adquirir una preponderancia en la narración. Los relojes comienzan a sonar, cada vez más rápido. "El tiempo avanza cada día más rápido”, dice Zoila a María. “Ocho de la mañana o quizá ya sean las once. Ya no es posible confiar en los relojes” (109). Cuando María atenta contra la fruta provocando con ello su propia disolución, entonces el tiempo adquiere una fuerza definitiva. La irrupción del final que el capitalismo de la producción en serie y de la ciencia se esmeran en retrasar, la intervención de ese gesto contra la permanencia, la Mayor ahora unida a la Menor, han comenzado a activar el tiempo, la finitud de lo existente y el horizonte de la existencia comienzan a cobrar fuerza:

El tiempo resuena, se reitera. Sería incapaz de distinguir la hora desde aquí, las manecillas se han vuelto borrosas. Esas manecillas alteradas que ahora anuncian las nueve y media. Minutos después, cuando empiezan a dar otra vez el cuarto, mi hermana los maldice: ¡que se callen!, dice con el hilo de voz que le queda, ique dejen de recordarme que pasa la hora! ¡Haz que se callen!, me ordena tapándose las orejas. (Fruta podrida 109)

Pero aunque se destrocen los relojes, el tiempo ha comenzado a actuar, el final, la impermanencia ya no abandonará las vidas desatadas que ellas han comenzado a construir. Asimismo, al final de Mano de obra, Gabriel, el reponedor se propone, al ser despedido del súper y desarticulado su precario hogar, construir una nueva forma de organización que se hace esta vez disponible. Es él quien desde el comienzo de la novela

Revista Iberoamericana, Vol. LXXXII, Núm. 254, Enero-Marzo 2016, 27-43 ISSN 0034-9631 (Impreso)

ISSN 2154-4794 (Electrónico) 
se presentó como una línea de fuga, quien inquieta constantemente a los otros con sus quejas y sus críticas al súper. Es Gabriel quién conformará una nueva organización y que exige derecho de ciudadanía en un Chile moderno y cosmopolita, cerrando el libro con estas palabras: "vamos a cagar a los maricones que nos miran como si nosotros no fuéramos chilenos. Sí, como si no fuéramos chilenos igual que todos los demás culiados chuchas de su madre. Ya pues huevones, caminen. Caminemos. Demos vuelta la página" (Eltit 176).

\section{BiBLIOGRAFÍA}

Agamben, Giorgio. Profanaciones. Buenos Aires: Adriana Hidalgo, 2005.

Barrientos, Mónica. "Vigilancia y fuga en Mano de obra de Diamela Eltit". Narrativas 5 (2007): 26-31.

Benjamin, Walter. Selected Writings. Vol. I. Cambridge-London: Belknap P of Harvard UP, 1996.

Blanco, Fernando. "Poéticas de alienación y muerte". Letras y proclamas: la estética literaria de Diamela Eltit. Bernardita Llanos M., ed. Santiago de Chile/Granville: Editorial Cuarto Propio/Denison University, 1996.

Cánovas, Rodrigo. “Diamela Eltit. Algunos años antes, algunos años después”. Diamela Eltit: redes locales, redes globales. Rubí Carreño Bolívar, ed. Frankfurt am Main: Vervuert, 2009. 25-32.

Carreño Bolívar, Rubí, ed. Diamela Eltit: redes locales, redes globales. Frankfurt am Main: Vervuert, 2009.

Eliade, Mircea. Lo sagrado y lo profano. Barcelona: Paidós, 1998.

Eltit, Diamela. Mano de obra. Santiago de Chile: Editorial Planeta Chilena, 2002. Foucault, Michel. Las tecnologías del yo y otros textos afines. Barcelona: Paidós, 1990. Fuguet, Alberto. "The World According to Jimmy Corrigan." apuntes autistas. $<$ http:// www.albertofuguet.cl/wordpress/?p=873-more-873>.

Guattari, Félix. Cartografias del deseo. Santiago de Chile: Francisco Zegers, 1989. Heidegger, Martin. Ser y tiempo. Santiago de Chile: Editorial Universitaria, 1998. Herlinghaus, Hermann. Violence Without Guilt: Ethical Narratives from the Global South. New York: Palgrave Macmillan 2009.

Lazzara, Michael J. “Estrategias de dominación y resistencia corporales: las biopolíticas del mercado en Mano de obra, de Diamela Eltit". Diamela Eltit: redes locales, redes globales. Rubí Carreño Bolívar, ed. Frankfurt am Main: Vervuert, 2009. 155-164. Llanos, Bernardita. "Pasiones maternales y carnales en la narrativa de Eltit". Letras y proclamas: la estética literaria de Diamela Eltit. Bernardita Llanos, ed. Granville/ Santiago de Chile: Editorial Cuarto Propio/Denison University, 1996. 103-141. Meruane, Lina. Fruta podrida. Santiago de Chile: Fondo de Cultura Económica, 2007. 
"Más mediocre que perverso". El Mercurio. 22 dic. 2006. <http://www.letras. s5.com/lm221206.htm>. 20 marzo 2010.

"Todo sobre la peste. Entrevista con Patricio Jara". El Mercurio. 4 nov. 2007. $<$ http://letras.s5.com/lm160309.html>. 17 feb. 2011.

Ricoeur, Paul. Historia y narratividad. Barcelona: Ediciones Paidós Ibérica-I.C.E. de la Universidad Autónoma de Barcelona, 1999. 
